\title{
Muscle Weakness Lower Limb
}

National Cancer Institute

\section{Source}

National Cancer Institute. Muscle Weakness Lower Limb. NCI Thesaurus. Code C78456.

A reduction in the strength of the lower limb muscles. 